\title{
Glutathione S-transferase M1-null genotype as risk factor for SOS in oxaliplatin-treated patients with metastatic colorectal cancer
}

\author{
C P H Vreuls ${ }^{*, 1}$, S W M Olde Damink ${ }^{2,3}$, G H Koek ${ }^{4}$, A Winstanley ${ }^{5}$, E Wisse ${ }^{6}, \mathrm{R} \mathrm{H} \mathrm{E} \mathrm{Cloots}{ }^{1}$,
} M A J van den Broek ${ }^{2}$, C H C Dejong ${ }^{2}, \mathrm{~F} \mathrm{~T} \mathrm{Bosman}{ }^{7}$ and A Driessen ${ }^{1}$

${ }^{1}$ Department of Pathology, Maastricht University Medical Centre, Maastricht, The Netherlands; ${ }^{2}$ Department of Surgery, Maastricht University Medical Centre and NUTRIM School for Nutrition, Toxicology and Metabolism, Maastricht, The Netherlands; ${ }^{3}$ Department of HPB Surgery and Liver Transplantation, Royal Free Hospital, University College London, London, UK; ${ }^{4}$ Department of Internal Medicine, Division of Gastroenterology and Hepatology, Maastricht University Medical Centre, Maastricht, The Netherlands; ${ }^{5}$ Department of Pathology, University College London, London, UK; ${ }^{6}$ Electron Microscopy Unit, Maastricht University, Maastricht, The Netherlands and 'Department of Pathology, Erasmus University Medical Center, Rotterdam, The Netherlands

Background: Oxaliplatin is used as a neo-adjuvant therapy in hepatic colorectal carcinoma metastasis. This treatment has significant side effects, as oxaliplatin is toxic to the sinusoidal endothelial cells and can induce sinusoidal obstruction syndrome (SOS), which is related to decreased overall survival. Glutathione has an important role in the defence system, catalysed by glutathione $S$-transferase (GST), including two non-enzyme producing polymorphisms (GSTM1-null and GSTT1-null). We hypothesise that patients with a nonenzyme producing polymorphism have a higher risk of developing toxic injury owing to oxaliplatin.

Methods: In the nontumour-bearing liver, the presence of SOS was studied histopathologically. The genotype was determined by a semi-nested PCR.

Results: Thirty-two of the 55 (58\%) patients showed SOS lesions, consisting of 27\% mild, 22\% moderate and $9 \%$ severe lesions. The GSTM1-null genotype was present in 25 of the 55 (46\%). Multivariate analysis showed that the GSTM1-null genotype significantly correlated with the presence of (moderate-severe) SOS $(P=0.026)$.

Conclusion: The GSTM1-null genotype is an independent risk factor for SOS. This finding allows us, in association with other risk factors, to conceive a potential risk profile predicting whether the patient is at risk of developing SOS, before starting oxaliplatin, and subsequently might result in adjustment of treatment.

Colorectal cancer is responsible for 1.2 million new cancer cases and 608700 deaths in 2008 worldwide (Jemal et al, 2011). Fatal outcome as a rule is the result of metastatic disease. The liver is the most common site of metastases and at time of diagnosis $15-20 \%$ of the patients have already developed liver metastases (Adam, 2007). If the liver metastases can be removed completely by surgery, a 5 -year survival of $\sim 50 \%$ can be achieved (Choti et al, 2002; Fernandez et al, 2004). Most patients are not eligible for surgery, owing to the high number of liver metastases, their size and/or their location. Currently, these initially inoperable patients receive neo-adjuvant chemotherapy, for example, oxaliplatin and bevacizumab (Alberts et al, 2005; Jatoi et al, 2006), which might make the liver metastases operable and the patient potentially curable; this can be achieved in $15 \%$ of the patients with a 5-year survival of 33\% (Adam et al, 2004; Rubbia-Brandt et al, 2007). 
This approach, however, is associated with significant side effects. Up to $74 \%$ of the patients develop sinusoidal obstruction syndrome (SOS) (Rubbia-Brandt et al, 2004, 2010; Ward et al, 2008) in the nontumour-bearing liver, causing a higher incidence of postoperative complications and decreased overall survival (Nakano et al, 2008; Rubbia-Brandt, 2010; Tamandl et al, 2011). Sinusoidal obstruction syndrome is initiated by toxic injury to sinusoidal endothelial cells (SECs), which can cause different degrees of vascular damage, namely sinusoidal obstruction, perisinusoidal fibrosis, centrilobular hepatic vein fibrotic obstruction, nodular regenerative hyperplasia (NRH) and peliosis (Rubbia-Brandt, 2010).

The cytotoxicity of oxaliplatin, a platinum drug, is caused by intrastrand crosslinks between platinum and DNA, eventually leading to tumour cell apoptosis (Rabik and Dolan, 2007). Cellular defence is possible by DNA repair mechanisms and inactivation of the platinum compound by glutathione and other anti-oxidants (Wang et al, 2000; Kweekel et al, 2005; Rabik and Dolan, 2007; Furuta, 2009). Glutathione forms an adduct with platinum, subsequently leading to detoxification of oxaliplatin. This adduct formation is catalysed by glutathione $S$-transferase enzyme (GST) (Kweekel et al, 2005). Several subclasses of GST are known, in which $\theta$ (GSTT), $\mu$ (GSTM), $\alpha$ (GSTA), $\pi$ (GSTP) and $\omega$ (GSTO) are best characterised, each with their own polymorphism (Di Pietro et al, 2010). In contrast to the other known polymorphisms, both GSTT and GSTM have a null genotype, respectively, GSTT1null and GSTM1-null. The null genotypes concern a complete gene deletion, resulting in no functional enzymatic activity. Lack of enzymatic GST function leads to a decreased adduct formation between glutathione and platinum and, consequently, a decreased defence mechanism against oxaliplatin (Kweekel et al, 2005; Furuta, 2009).

Not every patient develops SOS (Rubbia-Brandt et al, 2004, 2010; Ward et al, 2008); this individual vulnerability might result from deficiencies in the detoxification process. As GST is a part of the cellular defence mechanism, we hypothesised that patients with a GSTT1-null and/or GSTM1-null genotype have a higher risk of developing the toxic injury owing to oxaliplatin, namely SOS. Among the studied risk factors (Nakano et al, 2008), a genetic factor has not been reported so far. Identification of such a risk factor might be clinically important, as therapies aiming at the prevention of SOS are currently under study (Lehmann et al, 2012). The aim of this study was to research the impact of the GSTM1-null and/or GSTT1-null genotypes on the risk of developing SOS, in oxaliplatin-treated patients with colorectal liver metastases.

\section{MATERIALS AND METHODS}

Patients. Included were all patients with colorectal liver metastases, who initially underwent a partial hepatic resection at the Maastricht University Medical Centre between January 2008 and December 2009. Exclusion criteria were: no neo-adjuvant treatment or neo-adjuvant treatment not containing oxaliplatin or non-adequate histopathological material (e.g., no presence of nontumour-bearing liver on a distance of more than $2 \mathrm{~cm}$ from the tumour). The basic treatment schedule was 6 cycles of oxaliplatin $\left(130 \mathrm{mg} / \mathrm{m}^{2}\right.$ once in 3 weeks). The actual number of treatment cycles differed per patient, depending on the radiological response according to Response Criteria In Solid Tumours (Husband et al, 2004), in combination with the patient's physical condition and the sustained side effects (e.g., neurotoxicity). The study was performed in accordance with the ethical standards of the Declaration of Helsinki, and written informed consent was obtained from each patient.
Methods. The hepatectomy specimens were sliced before fixation. After fixation (4\% buffered formaldehyde), several tissue samples were taken from the nontumour-bearing liver (at a minimum distance of $2 \mathrm{~cm}$ from the lesion), avoiding the subcapsular region. The tissue samples were routinely embedded in paraffin and $4 \mu \mathrm{m}$ sections were cut.

Sinusoidal obstruction syndrome. Morphological analysis was based on haematoxylin and eosin, reticulin and Trichrome Masson stains. Histopathological features containing vascular and parenchymal changes were graded categorically, according to the scheme of Rubbia-Brandt et al (2010).

Based on these criteria, sinusoidal dilatation was graded as follows: 0, absent; 1, mild (centrilobular involvement limited to one-third of the lobular area); 2, moderate (centrilobular involvement extending in two-thirds of the lobular area) and 3, severe (complete lobular involvement or centrilobular involvement extending to adjacent lobules with bridging congestion). All histological sections were examined by two experienced hepatobiliary pathologists $(\mathrm{AD}-\mathrm{AW})$, unaware of the clinical data and the GSTM1 and GSTT1 polymorphism; in case of discrepancy, the section was discussed at the dual head microscope and consensus was reached.

GSTM1 and GSTT1 polymorphism analysis. The genomic DNA was extracted from formalin-fixed, paraffin-embedded nontumour-bearing liver tissue samples, with the Puregene DNA Isolation Kit (Gentra Systems, Minneapolis, MN, USA). The manufacter's protocol was followed, using 10 thick $(10 \mu \mathrm{m})$ macrodissected sections. The DNA purity was controlled by the NanoDrop ND-1000 Spectrophotometer (Isogen Life Sciences, De Meern, The Netherlands). Products with an A260/A280 ratio between 1.8 and 2.0 were regarded as pure and protein-free DNA.

A semi-nested multiplex PCR was used for simultaneous assessment of the GSTM1 and GSTT1 genes, using $\beta$-globine as an internal control. The semi-nested technique was indicated owing to the DNA extraction from paraffin-embedded tissue and the length of the fragments (219-290 base pairs), as a semi-nested PCR is more successful in specifically amplifying long DNA products compared with conventional PCR.

The first PCR product ( $1: 100$ dilution) served as a template for the second PCR. In each PCR, one round of 35 cycles was performed. The primer sequences, of both first and second PCR, are listed in Table 1. Subsequently, electrophoretic analysis was performed, visualising the amplified product by gelstar in a $2 \%$ agarose gel.

As one of the primers is located in the deleted sequence, this technique enabled us to identify the homozygous null genotype. However, differentiation between the deletional heterozygotes and the nondeletional homozygotes is not possible, both of which we defined as GSTM1-positive or GSTT1-positive genotype.

Statistics. For statistical analysis, we combined the absence of SOS lesions (grade 0 ) and mild lesions (grade 1), and also the moderate (grade 2) and severe (grade 3) SOS lesions, resulting into two groups (absent-mild lesions and moderate-severe lesions). A multivariate logistic regression analysis was used to correlate the GSTM1-null genotype, GSTT1-null genotype, GSTM1-null/ GSTT1-null genotype and cumulative amount of oxaliplatin, in the presence of SOS $(0=$ absent-mild and $1=$ moderate-severe $)$. As applicable, a $\chi^{2}$ test or Student $t$-test was used for analysis of baseline features of the different groups, concerning GSTM1-null and GSTM1-pos. All statistical analyses were performed using SPSS 15.0 statistical software (SPSS, Chicago, IL, USA). For all tests, $P<0.05$ was considered to indicate statistical significance. 


\begin{tabular}{|c|c|c|}
\hline Primer designation & Sequences & $\begin{array}{l}\text { Product } \\
\text { length } \\
\text { (bp) }\end{array}$ \\
\hline \multicolumn{3}{|l|}{ GSTM1 } \\
\hline $\begin{array}{l}\text { First amplification } \\
\text { Forward } \\
\text { Reverse }\end{array}$ & $\begin{array}{l}\text { 5'-GAACTCCCTGAAAAGCTAAAGC-3' } \\
\text { 5'-GTTGGGCTCAAATATACGGTGG-3' }\end{array}$ & 219 \\
\hline $\begin{array}{l}\text { Second amplification } \\
\text { Forward } \\
\text { Reverse }\end{array}$ & $\begin{array}{l}\text { 5'-CAGAGTTTCTGGGGAAGCGG-3' } \\
\text { idem first amplification }\end{array}$ & 191 \\
\hline \multicolumn{3}{|l|}{ GSTT1 } \\
\hline $\begin{array}{l}\text { First amplification } \\
\text { Forward } \\
\text { Reverse }\end{array}$ & $\begin{array}{l}\text { 5'-TTCCTTACTGGTCCTCACATCTC-3' } \\
\text { 5'-AAGACTTGGCAGCCAGCACC-3' }\end{array}$ & 290 \\
\hline $\begin{array}{l}\text { Second amplification } \\
\text { Forward } \\
\text { Reverse }\end{array}$ & $\begin{array}{l}\text { idem first amplification } \\
\text { 5'-TACAGACTGGGGATGGATGG-3' }\end{array}$ & 249 \\
\hline \multicolumn{3}{|l|}{$\beta$-globine } \\
\hline $\begin{array}{l}\text { First amplification } \\
\text { Forward } \\
\text { Reverse }\end{array}$ & $\begin{array}{l}\text { 5'-GAAGAGCCAAGGACAGGTAC-3' } \\
\text { 5'-CAACTTCATCCACGTTCACC-3' }\end{array}$ & 268 \\
\hline $\begin{array}{l}\text { Second amplification } \\
\text { Forward } \\
\text { Reverse }\end{array}$ & $\begin{array}{l}\text { 5'-GGCTGGGCATAAAAGTCAGG-3' } \\
\text { idem first amplification }\end{array}$ & 162 \\
\hline \multicolumn{3}{|c|}{$\begin{array}{l}\text { Abbreviations: bp }=\text { base pairs; GSTM }=\text { glutathione } S \text {-transferase enzyme } \mu \text {; GSTT }= \\
\text { glutathione } S \text {-transferase enzyme } \theta \text {. }\end{array}$} \\
\hline
\end{tabular}

\section{RESULTS}

Patients. Between January 2008 and December 2009, 80 Caucasian patients underwent a first partial hepatectomy for colorectal liver metastases at the Maastricht University Medical Centre. After excluding patients for no neo-adjuvant treatment or neo-adjuvant treatment not containing oxaliplatin $(n=22)$ and lack of adequate histopathological material $(n=3), 55$ patients were available for analysis. There were 28 males and 27 females, mean age 62 years (range 40-81). All patients received oxaliplatin with a median number of six cycles (range 1-12), leading to a mean cumulative dose of OX $650 \mathrm{mg} \mathrm{m}^{-2}$ (range 130-1560), all over treatment. Thirty-eight patients received additional bevacizumab.

SOS, GSTM1 and GSTT1 genotype. Thirty-two of the 55 (58\%) patients showed SOS lesions, resulting in 69\% absent-mild and $31 \%$ moderate-severe. The cumulative dose of oxaliplatin showed a significant difference between the absent-mild and moderatesevere group ( $649 \mathrm{mg} \mathrm{m}^{-2}$ vs $818 \mathrm{mg} \mathrm{m}^{-2}$; $P=0.040$ ).

The DNA purity, measured in A260/A280, had a mean value of 1.92 (range 1.89-1.99), concluding that the samples were pure and protein-free. Twenty-five of the 55 (46\%) patients had the GSTM1-null genotype. The GSTM1-null genotype showed a significantly higher incidence of moderate-severe SOS, compared with the GSTM1positive genotype ( $48 \%$ vs $17 \%, P=0.013$ ), (Table 2 ). The GSTT1-null genotype was present in 9 of the 55 (17\%) patients. Only four (7\%) patients had a combined GSTM1-null/GSTT1-null genotype.

Multivariate analysis showed that the GSTM1-null genotype correlated significantly with the presence of moderate-severe SOS $(P=0.026)$. The GSTT1-null genotype and the combined GSTM1-null/GSTT-null genotype showed no significant correlation $(P>0.05)$. Furthermore, the cumulative amount of oxaliplatin was positively correlated with the presence of moderate-severe SOS $(P=0.105)$ (Table 3$)$.

\section{DISCUSSION}

Sinusoidal obstruction syndrome is a frequent complication of oxaliplatin treatment. The clinical consequences may vary between longer hospitalisation and decreased overall survival (Nakano et al, 2008; Rubbia-Brandt, 2010; Tamandl et al, 2011). The present trial was designed to identify the presence of genetic variance in the glutathione allele as risk factor for SOS. We provide novel data that the GSTM1-null genotype is significantly positively related with the presence of moderate-severe SOS, making it an independent risk factor for the development of SOS.

In the nontumour-bearing liver, SOS covers a spectrum of pathological features consisting of sinusoidal obstruction, perisinusoidal fibrosis, centrolobular hepatic vein fibrotic obstruction, NRH and peliosis (Rubbia-Brandt, 2010). The initial damage occurs in the SECs, leading to detachment of the SECs and obstruction of the sinusoid (DeLeve et al, 1999). Better understanding of this initial damage and the SEC defence system is needed and might lead to new insights in the onset and, subsequently, the treatment of SOS.

The incidence of the GSTM1-null and the GSTT1-null genotype in our population was $46 \%$ and $17 \%$, respectively, which is comparable with the published literature for Caucasians (50\% and $20 \%$, respectively) (Dong et al, 2008). Our study showed that the GSTM1-null genotype was positively related with the presence of moderate-severe SOS, making it an independent risk factor for the development of SOS. This finding is consistent with the pathophysiology; the GSTM1-null genotype does not lead to an enzyme production, subsequently the binding of reactive platinum compounds to glutathione is not catalysed and the excessive damage to the SECs manifests itself in SOS. In addition, the GSTT1-null genotype seems to be less important in this process, as there was no correlation between the GSTT1-null genotype, nor the GSTM1-null/ GSTT1-null genotype, and SOS.

To our best knowledge, only one previous study by Srivastava et al (2004) has investigated the correlation between the GSTM1-null genotype and SOS, yet in another setting. In this study, bone marrow transplant patients were treated with busulfan and cyclophosphamide. Sinusoidal obstruction syndrome was diagnosed clinically, using the Baltimore criteria (Jones et al, 1987). They showed a significant positive correlation between the GSTM1-null genotype and SOS. Our study differs in treatment and diagnostic test, as we have diagnosed SOS histologically. Given the fact that both studies prove the importance of the GSTM1-null genotype supports the theory that glutathione has a key role in the pathogenesis of SOS. Deleve (1994) were the first to demonstrate this and to suggest that all SOS-inducing agents are more harmful for SECs than for hepatocytes, based on the lower glutathione levels in SECs (Wang et al, 2000). In addition, they showed that continuous glutathione infusion protects against SOS in an experimental rat model (Wang et al, 2000).

Although it is thought that glutathione has an important protective role in the initial damage, we noticed in our study that a few patients, which had the GSTM1-positive genotype, developed SOS. Several explanations for this finding should be considered. First, this finding might assume that the cumulative amount of oxaliplatin eventually determines whether a patient develops SOS. This leads us to the theory that every patient in the end develops SOS, if a sufficient dose of oxaliplatin is given. The cumulative amount, at which the patient develops SOS, depends on the patients vulnerability. Our data support this theory by a positive correlation between the cumulative dose of oxaliplatin and the presence of moderate-severe SOS $(P=0.105)$ (Table 3). Second, the initial toxic SEC damage is a multifactorial process, where in the human defence system glutathione has a role only partially. This defence system consists of DNA repair mechanisms and antioxidants (Wang et al, 2000; Kweekel et al, 2005; Rabik and Dolan, 
Table 2. Patient characteristics of the GSTM1-null and GSTM1-pos genotype groups

\begin{tabular}{|l|c|c|c|}
\hline Characteristics & GSTM1-null $(\boldsymbol{n}=\mathbf{2 5})$ & GSTM1-pos $(\boldsymbol{n}=\mathbf{3 0})$ & $\boldsymbol{P}$-value \\
\hline Sex, male, $n$ & 13 & 15 & 0.549 \\
\hline Age, mean \pm s.d. & $62 \pm 11$ & $62 \pm 10$ & 0.885 \\
\hline
\end{tabular}

Cumulative dose OX

\begin{tabular}{|l|c|c|c|}
\hline Mean \pm s.d., $\mathrm{mg} \mathrm{m}^{-2}$ & $735.6 \pm 271.7$ & $672.8 \pm 316.6$ & 0.432 \\
\hline Cycles, mean \pm s.d. & $6.1 \pm 2.7$ & $5.4 \pm 2.6$ & 0.347 \\
\hline Additional BV, $\mathrm{n}$ & 17 & 21 & 0.551 \\
\hline
\end{tabular}

SOS

\begin{tabular}{|l|c|c|}
\hline Absent-mild, $n$ & 13 & $0.013^{\star}$ \\
\hline Moderate-severe, $n$ & 12 & 25 \\
\hline
\end{tabular}

Abbreviations: BV = bevacizumab; GSTM = glutathione $\mathrm{S}$-transferase enzyme $\mu$; OX=oxaliplatin; $\mathrm{SOS}=$ sinusoidal obstruction syndrome.

*indicates significance.

Table 3. Regression coefficients $(\beta)$ with $95 \%$ confidence intervals from multivariate logistic regression analyses on the effect of the GSTM1-nul genotype, GSTTnull genotype, GSTM1-null/GSTT-null genotype and cumulative amount of OX, on the presence of SOS $(0=$ absent-mild, $1=$ moderate-severe)

\begin{tabular}{|l|c|c|}
\hline Prognostic factors & $\begin{array}{c}\text { SOS regression coefficient } \\
(\mathbf{9 5 \%} \mathrm{Cl})\end{array}$ & $\boldsymbol{P}$-value \\
\hline GSTM1-null genotype & $-1.690(0.042-0.817)$ & $0.026^{*}$ \\
\hline GSTT1-null genotype & $-0.617(0.041-7.072)$ & 0.638 \\
\hline $\begin{array}{l}\text { GSTM1- and GSTT1-null } \\
\text { genotype }\end{array}$ & $0.429(0.051-46.14)$ & 0.805 \\
\hline $\begin{array}{l}\text { Cumulative dose OX } \\
\text { (mg m }{ }^{-2} \text { ) }\end{array}$ & $0.002(1.000-1.004)$ & 0.105 \\
\hline Additional BV & $-1.068(0.087-1.352)$ & 0.126 \\
\hline $\begin{array}{l}\text { Abbreviations: BV=bevacizumab; Cl, confidence interval; GSTM=glutathione S-transferase } \\
\text { enzyme } \mu \text {; GSTT=glutathione S-transferase enzyme } \theta ; \text { OX=oxaliplatin; SOS }=\text { sinusoidal } \\
\text { obstruction syndrome. } \\
\text { * indicates significance. }\end{array}$ \\
\hline
\end{tabular}

2007; Furuta, 2009), where the precise role of both, with regards to oxaliplatin, is not entirely clear. Improvement of the knowledge on the process of damage and the protection mechanisms involved might lead to the discovery of new treatment options of SOS and possibly also to preventive measures to avoid this injury.

A recent article by Rubbia-Brandt et al emphasises even more the genetic importance in the initial damage of SOS, as they described genes which are up- or downregulated in the presence of SOS, leading to a molecular signature. The oxidative stress pathway showed a major gene upregulation, which is meaningful in the initial SEC damage and cellular defence system (Rubbia-Brandt et al, 2011).

Our study harbours a limitation, as $69 \%$ of the patients have received additional bevacizumab, which has been shown to work protective against SOS (Rubbia-Brandt et al, 2010). Additional bevacizumab is recommended in the guidelines (Kabbinavar et al, 2005). As these patients are equally divided among both groups (GSTM1-null and GSTM1-pos), it is less likely that this drug would influence our results. However, a more ideal comparison would consist of patients solely treated with oxaliplatin.

In conclusion, the present study showed that the GSTM1-null genotype is significantly positively correlated with the presence of moderate-severe SOS, making it an independent risk factor for the development of SOS in oxaliplatin treatment. Our finding could contribute to a genetic risk profile, predicting whether the patient is at risk for developing SOS, before starting treatment, and may subsequently result in adjustment of the cumulative amount of oxaliplatin, but further prospective research is needed to evaluate this.

\section{ACKNOWLEDGEMENTS}

We thank Dr PJ Nelemans (Department of Epidemiology, Maastricht University) for her help in the statistical analysis.

\section{CONFLICT OF INTEREST}

The authors declare no conflict of interest.

\section{REFERENCES}

Adam R (2007) Colorectal cancer with synchronous liver metastases. Br J Surg 94: $129-131$.

Adam R, Delvart V, Pascal G, Valeanu A, Castaing D, Azoulay D, Giacchetti S, Paule B, Kunstlinger F, Ghemard O, Levi F, Bismuth H (2004) Rescue surgery for unresectable colorectal liver metastases downstaged by chemotherapy: a model to predict long-term survival. Ann Surg 240: 644-657; discussion 657-658.

Alberts SR, Horvath WL, Sternfeld WC, Goldberg RM, Mahoney MR, Dakhil SR, Levitt R, Rowland K, Nair S, Sargent DJ, Donohue JH (2005) Oxaliplatin, fluorouracil, and leucovorin for patients with unresectable liver-only metastases from colorectal cancer: a North Central Cancer Treatment Group phase II study. J Clin Oncol 23: 9243-9249.

Choti MA, Sitzmann JV, Tiburi MF, Sumetchotimetha W, Rangsin R, Schulick RD, Lillemoe KD, Yeo CJ, Cameron JL (2002) Trends in long-term survival following liver resection for hepatic colorectal metastases. Ann Surg 235: 759-766.

Deleve LD (1994) Dacarbazine toxicity in murine liver cells: a model of hepatic endothelial injury and glutathione defense. J Pharmacol Exp Ther 268: $1261-1270$

DeLeve LD, McCuskey RS, Wang X, Hu L, McCuskey MK, Epstein RB, Kanel GC (1999) Characterization of a reproducible rat model of hepatic veno-occlusive disease. Hepatology 29: 1779-1791.

Di Pietro G, Magno LA, Rios-Santos F (2010) Glutathione S-transferases: an overview in cancer research. Expert Opin Drug Metab Toxicol 6: 153-170.

Dong LM, Potter JD, White E, Ulrich CM, Cardon LR, Peters U (2008) Genetic susceptibility to cancer: the role of polymorphisms in candidate genes. JAMA 299: 2423-2436.

Fernandez FG, Drebin JA, Linehan DC, Dehdashti F, Siegel BA, Strasberg SM (2004) Five-year survival after resection of hepatic metastases from colorectal cancer in patients screened by positron emission tomography 
with F-18 fluorodeoxyglucose (FDG-PET). Ann Surg 240: 438-447; discussion 447-450.

Furuta T (2009) Pharmacogenomics in chemotherapy for GI tract cancer. J Gastroenterol 44: 1016-1025.

Husband JE, Schwartz LH, Spencer J, Ollivier L, King DM, Johnson R, Reznek R (2004) Evaluation of the response to treatment of solid tumours - a consensus statement of the International Cancer Imaging Society. Br J Cancer 90: 2256-2260.

Jatoi A, Murphy BR, Foster NR, Nikcevich DA, Alberts SR, Knost JA, Fitch TR, Rowland Jr KM (2006) Oxaliplatin and capecitabine in patients with metastatic adenocarcinoma of the esophagus, gastroesophageal junction and gastric cardia: a phase II study from the North Central Cancer Treatment Group. Ann Oncol 17: 29-34.

Jemal A, Bray F, Center MM, Ferlay J, Ward E, Forman D (2011) Global cancer statistics. CA Cancer J Clin 61(2): 69-90.

Jones RJ, Lee KS, Beschorner WE, Vogel VG, Grochow LB, Braine HG, Vogelsang GB, Sensenbrenner LL, Santos GW, Saral R (1987) Venoocclusive disease of the liver following bone marrow transplantation. Transplantation 44: 778-783.

Kabbinavar FF, Schulz J, McCleod M, Patel T, Hamm JT, Hecht JR, Mass R, Perrou B, Nelson B, Novotny WF (2005) Addition of bevacizumab to bolus fluorouracil and leucovorin in first-line metastatic colorectal cancer: results of a randomized phase II trial. J Clin Oncol 23: 3697-3705.

Kweekel DM, Gelderblom H, Guchelaar HJ (2005) Pharmacology of oxaliplatin and the use of pharmacogenomics to individualize therapy. Cancer Treat Rev 31: 90-105.

Lehmann K, Rickenbacher A, Weber A, Pestalozzi BC, Clavien PA (2012) Chemotherapy before liver resection of colorectal metastases: friend or foe? Ann Surg 255: 237-247.

Nakano H, Oussoultzoglou E, Rosso E, Casnedi S, Chenard-Neu MP, Dufour P, Bachellier P, Jaeck D (2008) Sinusoidal injury increases morbidity after major hepatectomy in patients with colorectal liver metastases receiving preoperative chemotherapy. Ann Surg 247: $118-124$.

Rabik CA, Dolan ME (2007) Molecular mechanisms of resistance and toxicity associated with platinating agents. Cancer Treat Rev 33: 9-23.

Rubbia-Brandt L (2010) Sinusoidal obstruction syndrome. Clin Liver Dis 14: 651-668.

Rubbia-Brandt L, Audard V, Sartoretti P, Roth AD, Brezault C, Le Charpentier M, Dousset B, Morel P, Soubrane O, Chaussade S, Mentha G, Terris B (2004) Severe hepatic sinusoidal obstruction associated with oxaliplatin-based chemotherapy in patients with metastatic colorectal cancer. Ann Oncol 15: 460-466.

Rubbia-Brandt L, Giostra E, Brezault C, Roth AD, Andres A, Audard V, Sartoretti P, Dousset B, Majno PE, Soubrane O, Chaussade S, Mentha G, Terris B (2007) Importance of histological tumor response assessment in predicting the outcome in patients with colorectal liver metastases treated with neo-adjuvant chemotherapy followed by liver surgery. Ann Oncol 18: 299-304.

Rubbia-Brandt L, Lauwers GY, Wang H, Majno PE, Tanabe K, Zhu AX, Brezault C, Soubrane O, Abdalla EK, Vauthey JN, Mentha G, Terris B (2010) Sinusoidal obstruction syndrome and nodular regenerative hyperplasia are frequent oxaliplatin-associated liver lesions and partially prevented by bevacizumab in patients with hepatic colorectal metastasis. Histopathology 56: 430-439.

Rubbia-Brandt L, Tauzin S, Brezault C, Delucinge-Vivier C, Descombes P, Dousset B, Majno PE, Mentha G, Terris B (2011) Gene expression profiling provides insights into pathways of oxaliplatin-related sinusoidal obstruction syndrome in humans. Mol Cancer Ther 10: 687-696.

Srivastava A, Poonkuzhali B, Shaji RV, George B, Mathews V, Chandy M, Krishnamoorthy R (2004) Glutathione S-transferase M1 polymorphism: a risk factor for hepatic venoocclusive disease in bone marrow transplantation. Blood 104: 1574-1577.

Tamandl D, Klinger M, Eipeldauer S, Herberger B, Kaczirek K, Gruenberger B, Gruenberger T (2011) Sinusoidal obstruction syndrome impairs long-term outcome of colorectal liver metastases treated with resection after neoadjuvant chemotherapy. Ann Surg Oncol 18: 421-430.

Wang X, Kanel GC, DeLeve LD (2000) Support of sinusoidal endothelial cell glutathione prevents hepatic veno-occlusive disease in the rat. Hepatology 31: $428-434$.

Ward J, Guthrie JA, Sheridan MB, Boyes S, Smith JT, Wilson D, Wyatt JI, Treanor D, Robinson PJ (2008) Sinusoidal obstructive syndrome diagnosed with superparamagnetic iron oxide-enhanced magnetic resonance imaging in patients with chemotherapy-treated colorectal liver metastases. J Clin Oncol 26: 4304-4310.

This work is published under the standard license to publish agreement. After 12 months the work will become freely available and the license terms will switch to a Creative Commons AttributionNonCommercial-Share Alike 3.0 Unported License. 